\title{
Effects of Age, Sex, and Neuropsychological Performance on Financial Decision-Making
}

\author{
Sara K. Shivapour ${ }^{1}$, Christopher M. Nguyen ${ }^{1,2}$, Catherine A. Cole $^{3}$ and Natalie L. Denburg ${ }^{1 *}$ \\ ${ }^{1}$ Division of Cognitive Neuroscience, Department of Neurology, University of lowa Carver College of Medicine, lowa City, IA, USA \\ 2 Department of Psychological and Quantitative Foundations, University of lowa College of Education, lowa City, IA, USA \\ ${ }^{3}$ Department of Marketing, University of lowa Tippie College of Business, lowa City, IA, USA
}

Edited by:

K. Richard Ridderinkhof, University of Amsterdam, Netherlands

\section{Reviewed by:}

Bernd Weber,

Rheinische-Friedrich-Wilhelms

Universität, Germany

Carolyn Yoon, University of Michigan, USA

\section{*Correspondence:}

Natalie L. Denburg, Department of Neurology, University of lowa Hospitals and Clinics, \#2007 RCP, 200

Hawkins Drive, lowa City, IA 52242-1053, USA.

e-mail: natalie-denburg@uiowa.edu
The capacity to make sound financial decisions across the lifespan is critical for interpersonal, occupational, and psychological health and success. In the present study, we explored how healthy younger and older adults make a series of increasingly complex financial decisions. One-hundred sixteen healthy older adults, aged 56-90 years, and 102 college undergraduates, completed the Financial Decision-Making Questionnaire, which requires selecting and justifying financial choices across four hypothetical scenarios and answering questions pertaining to financial knowledge. Results indicated that Older participants significantly outperformed Younger participants on a multiple-choice test of acquired financial knowledge. However, after controlling for such pre-existing knowledge, several age effects were observed. For example, Older participants were more likely to make immediate investment decisions, whereas Younger participants exhibited a preference for delaying decision-making pending additional information. Older participants also rated themselves as more concerned with avoiding monetary loss (i.e., a prevention orientation), whereas Younger participants reported greater interest in financial gain (i.e., a promotion orientation). In terms of sex differences, Older Males were more likely to pay credit card bills and utilize savings accounts than were Older Females. Multiple positive correlations were observed between Older participants' financial decision-making ability and performance on neuropsychological measures of non-verbal intellect and executive functioning. Lastly, the ability to justify one's financial decisions declined with age, among the Older participants. Several of the aforementioned results parallel findings from the medical decision-making literature, suggesting that older adults make decisions in a manner that conserves diminishing cognitive resources.

Keywords: aging, decision-making, financial, cognition

\section{INTRODUCTION}

The population of the United States (US) has undergone a dramatic age shift in the last 10 years. To ignore predictions that this trend will significantly accelerate in future years may have catastrophic societal ramifications. In 2008, approximately 39 million US citizens were age 65 or older, constituting nearly $13 \%$ of Americans (Federal Interagency Forum on Aging-Related Statistics, 2010). However, as the baby boomer generation enters this age bracket, the older adult population is forecasted to exceed 70 million Americans by 2030, totaling one-fifth of the US population (He et al., 2005). In fact, with nearly every country anticipated to undergo dramatic population aging in the near future, major implications throughout the economic, social, and political world can be expected (United Nations, 2009).

In the US, the growing population of older adults will be characterized by increased racial diversity and higher educational attainment than any preceding generation, as well as a net worth that has risen $80 \%$ in the last 20 years (Federal Interagency Forum on Aging-Related Statistics, 2010). Increasing longevity, geographical dispersion, and the modern emphasis on self-reliance will require older adults to maintain complex decision-making faculties as they age (Finucane et al., 2002). Financial decision-making abilities, in particular, will be critical for this population segment, which has benefited from a higher level of prosperity than any of its elder generational predecessors, as measured by a steady rise in incomes for older Americans since 1976 and a decrease in elders living below the poverty line (Federal Interagency Forum on Aging-Related Statistics, 2010).

To increase the opportunities available to older adults and facilitate optimal decision-making, lawmakers often assume that more information and disclosures will help elders tailor choices to their specific needs and desires. It remains unclear, however, whether older adults are able to use such information to their benefit in complex domains, such as health care or financial decisionmaking. In an analysis of decision-making capacity when evaluating health care plans, Finucane et al. (2002) found that older adults displayed inferior comprehension, regardless of the information being presented and the complexity of the question. As age increased, participants revealed significantly more comprehension errors and slightly greater inconsistencies in preference 
when choosing a health plan, even after controlling for sex, education, income, health, self-rated skill, and attitude. Considering the simplicity of their stimuli compared to real-world health care contracts, the rate of comprehension difficulties among older adults warrants cause for serious concern (Finucane et al., 2002).

These findings are in keeping with literature regarding the effects of marketing on older consumers (John and Cole, 1986; Yoon et al., 2009), which suggest that older adults may encounter difficulties in decision-making when presented with large amounts of data. The most significant declines in decision-making performance by older consumers occurred during unfamiliar tasks that contained large quantities of information, had formats that hindered encoding, with limited guidance to aid information processing, and demanding answer formats. These authors recommended that future experimental stimuli (as well as public policy) targeting older adults focus on keeping information limited, well organized, and integrated with visual stimuli as appropriate.

The need for well-validated measures of decision-making capacity able to assess individual fitness to perform a task or make a decision autonomously will only rise as the population of older adults grows, with simultaneously increasing rates of cognitive deficits, dementia, other medical and neurological illnesses, and risk for elder abuse or exploitation within this group. This task is formidable, as no widely accepted instrumental validity standard for capacity assessment currently exists, with prior assessments having been made on the presence or absence of a medical diagnosis or global indicator of mental status (Moye and Marson, 2007). Of course, an additional important goal for future measures must be their ability to be tailored to individuals so that areas in need of protection can be identified without disqualifying or restricting rights in which full capacity remains. With the shift to identification and assessment of such task-related capacity domains, it becomes equally necessary to validate new measures - and new constructs - using convergence with other indicators of capacity (i.e., clinical diagnosis), cognitive tests, and consistency over time (Moye and Marson, 2007). One critical area for future assessment will be financial decision-making competence, as this skill is crucial not only to retaining autonomy in society, but also requires the use of intact higher-order cognitive functioning (Moye and Marson, 2007).

The majority of work assessing financial skill has been carried out in neurological populations. Marson et al. (2000) created the Financial Capacity Instrument (FCI), a standardized, psychometric, technician-administered instrument based on their tripartite model which views financial decision-making as requiring: (1) basic declarative knowledge (e.g., knowledge of currency); (2) procedural knowledge (e.g., writing checks); and (3) higherorder judgment, or the ability to evaluate novel or ambiguous situations and make financial decisions in one's best interest (Moye and Marson, 2007). Not surprisingly, patients with mildly severe Alzheimer's disease demonstrated emerging global impairment across most financial tasks and most domains, whereas patients with moderately severe Alzheimer's disease demonstrated advanced global impairment across all financial tasks and domains (Marson et al., 2000). Defects in complex financial skills, such as checkbook management and bank statement management, were also observed in individuals with mild cognitive impairment as compared to healthy older adults. Furthermore, patients with MCI who had converted to Alzheimer's disease by the 1-year follow-up exhibited significantly greater declines in procedural skills, such as bill payment and cash transactions, despite intact conceptual understanding of each item (Triebel et al., 2009).

Lusardi (2010) examined the financial capabilities of the American public across four general domains: living within one's means, planning for the future, navigating financial products (e.g., credit cards, stocks, mortgages), and financial literacy. Data from the National Financial Capability Study showed that the average American reports higher levels of knowledge than those actually displayed on tests of financial capacity, and that the costs of such disparity is being evidenced in failure to plan for retirement or emergencies and poor investment choices, particularly among those with low income and education.

In a study of financial knowledge and its relation to successful retirement planning, Lusardi and Mitchell (2011b) found that only $50 \%$ of adults aged 50 years and older could correctly respond to questions regarding interest compounding and inflation. Moreover, less than $20 \%$ of the older adult sample felt that their retirement planning had been successful, with those displaying the highest levels of financial knowledge being most likely to have placed money in savings accounts or more complex investments (e.g., stocks, mutual funds) (Boersch-Supan and Essig, 2005).

International research shows high rates of financial illiteracy in both well-developed markets, such as Germany, Japan, and Sweden, as well as those that are quickly changing (e.g., Russia). Individuals with the highest level of financial knowledge are the most likely to successfully plan for their own retirement, however, older adults have been shown across numerous countries to routinely overestimate their level of financial knowledge when asked to complete basic financial measures (Lusardi and Mitchell, 2011a). A longitudinal study of the investment strategies of German nationals found that over $70 \%$ of the German population had their assets in a conventional savings account, whereas only $20 \%$ of older adults reported holding any stocks or mutual funds compared with $40 \%$ of younger adults (aged 35 years and below). Though younger adults placed a larger portion of their income into savings accounts relative to older adults, the latter were considerably more likely to report that they "always have a lot" or "often have some" money left at the end of each month.

The anterior portion of the frontal lobe, responsible for reasoning, judgment, decision-making, and emotional processing, is a brain area that may be critical for sound financial decision-making ability. A series of studies by Denburg et al. $(2005,2006,2007)$ and Denburg and Harshman (2010) showed that a sizeable portion of neurologically and psychiatrically healthy older adults might nevertheless suffer from impaired decision-making skills due to subclinical dysfunction within a neural system that includes the ventromedial prefrontal cortex (VMPC). Age-related declines were evidenced by a large subset of healthy, older adults (35-40\%) using the Iowa Gambling Task (IGT; Bechara, 2007), a well-validated laboratory test of decision-making. Compared to unimpaired older adults, those with decision-making deficits ("impaired") failed to shift their choices from Bad to Good decks as the task progressed, instead making disadvantageous choices throughout, in a manner consistent with VMPC lesion patients (Denburg et al., 2005). Too, 
these impaired older adults evidenced abnormal somatic states (Denburg et al., 2006) as well as higher rates of falling prey to misleading and deceptive advertising (Denburg et al., 2007).

The present study involved an exploratory analysis examining how healthy younger and older adults make a series of increasingly complex financial decisions. Additionally, among the older adults, we examined how males and females may differ in their financial decision-making. Finally, the association between neuropsychological (i.e., intelligence, attention, working memory, numerical skill, visual spatial, language, memory, and executive function) variables to financial decision-making ability was investigated.

\section{MATERIALS AND METHODS PARTICIPANTS}

Participants were 116 community-dwelling older adults, aged 5690 years (63\% female), and 102 college undergraduates ${ }^{1}$ attending The University of Iowa Tippie College of Business. The health of the Older participants was confirmed via a semi-structured screening interview that assessed neurological status, current medications, alcohol/drug consumption, and mood (after Tranel et al., 1997).

\section{MEASURES}

\section{Financial Decision-Making Questionnaire (FDMQ)}

This questionnaire assessed financial knowledge and decisionmaking ability (Cole and Denburg, 2008). Participants proceed through four hypothetical scenarios, in which they receive increasingly complex financial information and are asked to select between the options provided and to justify each decision. In Scenario 1 (hereafter referred to as Personal Finance), the measure lists a monthly income, interest rates (for both a credit card and savings account), and bills due (i.e., rent, credit card statement) for a fictional individual; respondents are then asked to allocate the available assets for the month using the information provided among three options: (1) rent, (2) credit card bill, and (3) savings account. Following this choice is a short answer portion in which participants are asked to provide justification for each monetary decision.

In Scenario 2 (hereafter referred to as Impulse Purchase), participants are asked to recall the same hypothetical individual from Scenario 1, and to imagine that this individual chose not to pay his/her credit card debt from the previous bill. They are then told that this person has just passed a storefront where the TV that he/she wishes to buy has been placed on sale for a discount of $50 \%$ off the original price. Keeping in mind that the individual is currently carrying an unpaid credit card balance from the preceding month, participants are asked in Scenario 2 to indicate whether or not they would purchase the discounted TV using the credit card if they were in this situation and to provide justification for their decision.

Next, participants are supplied with a small table detailing various financial investment options (e.g., Savings Account, Certificate of Deposit, Mutual Fund). This begins Scenario 3 (hereafter referred to as Low Precision Investment), in which participants are

${ }^{1}$ For the undergraduate sample, limited demographic information was available, and neuropsychological evaluation was not performed. asked to imagine that they have just inherited $\$ 20,000$ unexpectedly. Below the table, participants are asked to indicate whether or not they would make an immediate decision regarding how to allocate the inheritance between the options listed. Those who indicate "Yes" are asked to proceed to Scenario 4 on the following page; participants who answer "No" in Scenario 3 are asked to please indicate what additional information they would seek before being able to make a decision regarding the allocation of these funds.

Scenario 4 (hereafter referred to as Financial Management) builds upon Scenario 3 in that participants receive an expanded investment table and are asked to complete it as though they have actually inherited $\$ 20,000$ and must now allocate the money accordingly. Participants may distribute the funds as they see fit across any of the options provided, including a Savings Account, Certificate of Deposit, Business Venture, Payment of Credit Card Debt, Managed Mutual Fund, and Unmanaged Mutual Fund. Each option is presented with a brief description, including the interest rate, rate of return, and expected rate of loss for those to which it is applicable. Following the table, participants are asked to provide a justification for each allocation. Scenario 4 ends with two 7-point Likert scales, in which participants indicate how important making money and avoiding financial loss were to their decision-making process (hereafter referred to as Financial Behavior).

At the conclusion of the packet is a five-question quiz pertaining to financial knowledge. All of the questions are True/False in nature, and are written to be challenging to the average participant (hereafter referred to Acquired Financial Knowledge). (The Financial Decision-Making Questionnaire (FDMQ) is available by request to the corresponding author.)

\section{Neuropsychological battery}

Current and premorbid intelligence. Current intelligence was measured using the Wechsler Abbreviated Scale of Intelligence (WASI; Wechsler, 1999), which consists of four subtests (two verbal and two non-verbal): vocabulary, Similarities, Block Design, and Matrix Reasoning. The Vocabulary subtest asks participants to provide definitions for single words. In the Similarities subtest, a task of abstract verbal reasoning, participants are asked to state how two words are similar or alike. During the Block Design subtest, participants replicate two-dimensional patterns with redand white-colored blocks. In the Matrix Reasoning subtest, participants need to complete an unfinished visuospatial pattern by choosing from a five-alternative forced choice array. Premorbid intellect was measured using the Wide Range Achievement Test 3 (WRAT-3) Reading subtest (Wilkinson, 1993), a single-world reading task.

Attention and working memory. Simple and divided attention (also referred to as working memory) was measured with the Digit Span and Letter-Number Sequencing subtests from the Wechsler Adult Intelligence Scale - Third Edition (WAIS-III; Wechsler, 1997). In the Digit Span subtest, participants are asked to repeat strings of numbers in both a forward and backward order. During the Letter-Number Sequencing subtest, participants must recite back a string of jumbled numbers and letters by first sequencing the numbers followed by the letters. 
Numerical skill. Participants mentally solve increasingly difficult arithmetic problems in the Arithmetic subtest of the WAIS-III (Wechsler, 1997). We also measured participants' numeracy skill, defined as the ability to understand and use basic probability and mathematical concepts, via Lipkus' Numeracy Scale (Lipkus et al., 2001).

Visual spatial. The Rey-Osterrieth Complex Figure Test-Copy Condition (Rey-O Copy; Rey, 1941) consists of presenting a multipart figure, which the participant is instructed to copy. The copy performance measures both visual perception and visual construction. The Benton Facial Recognition Test (Benton Faces; Benton et al., 1994) is a measure of visual perceptual discrimination that requires the matching of identical or near-identical faces.

Language. The Controlled Oral Word Association Test (COWAT; Benton and Hamsher, 1989) is a verbal fluency measure, in which participants are given $1 \mathrm{~min}$ to say as many words as they can that begin with a designated letter. In the Boston Naming Test (BNT; Kaplan et al., 1983), a measure of confrontation naming, participants are presented with a series of line drawings, and have $20 \mathrm{~s}$ to correctly name each object. Here, we utilized a validated, short form of the BNT (Barrash et al., 1999).

Memory. The Rey Auditory-Verbal Learning Test (RAVLT; Rey, 1964 ) is a verbal learning and memory task. Participants are provided five trials to learn a list of 15 unrelated words. They are then asked to recite these words again following a 30-min incidental delay period. Visual memory was assessed with the Rey-Osterrieth Complex Figure Test-Delay Condition (Rey-O Delay; Rey, 1941), in which participants are asked to reproduce from memory the figure they copied 30 min previously. The Benton Visual Retention Test-Revised (BVRT-R; Benton, 1945) assessed short-term retention. Participants are asked to reproduce from immediate memory each of 10 designs containing one or more figures, following a 10-s study period.

Executive function. In the Wisconsin Card Sorting Test (WCST; Heaton et al., 1993), a measure of problem solving and mental flexibility, participants must correctly categorize cards based on immediate feedback. The Trail Making Test, Part B (Trail Making B; Spreen and Strauss, 1998), is a set-shifting task involving the alternation between numbers and letters. The IGT (Bechara, 2007) is a well-validated, computer-administered laboratory task of decision-making under ambiguity.

\section{PROCEDURES}

Older participants completed the aforementioned measures as part of a larger neuropsychological battery. Each testing session lasted approximately $3 \mathrm{~h}$, with a single experimenter working oneon-one with the older participant. There was no time limit on completion of the FDMQ, although Older participants generally completed the instrument in $30 \mathrm{~min}$ to $1 \mathrm{~h}$. As stated previously, the Younger participants completed only the FDMQ in a supervised classroom setting over a 50-min period; none of the undergraduate sample had difficulty finishing the questionnaire in the time allotted. Finally, calculators were not provided for completion of any portion of the FDMQ, however, participants could perform pencil and paper calculations as needed.

\section{DATA ANALYSIS}

Preliminary analyses were conducted to examine the data for the presence of outliers and the appropriateness of assumptions of linearity, independence of errors, and multicollinearity. Logistic regression analyses were then conducted to examine the contributions of Age Group (i.e., Younger vs. Older), Sex (i.e., Older Male vs. Older Female), and neuropsychological performance to financial decision-making, as measured by responses to the FDMQ Scenarios. The first set of regression analyses examined the contribution of Age to the FDMQ Scenarios. For each scenario, the variables of Age and FDMQ were entered into a predictive model to identify whether an individual was a Younger or Older participant. In the second set of regression analyses, which were limited to the Older participants, the contribution of Sex to the FDMQ Scenarios was examined and subsequently entered into a predictive model to identify whether an individual was a Male or Female participant. For each logistic model, Acquired Financial Knowledge was included in the analysis to control for pre-existing financial knowledge. Finally, among the Older participants, correlational analyses were conducted to examine the associations between responses to the FDMQ Scenarios and neuropsychological performance. As the study was exploratory, no adjustment was made for multiple testing.

\section{RESULTS}

\section{AGE ANALYSES}

Table 1 displays the results from the logistic regression analyses of responses to the FDMQ Scenarios between the Younger and Older participants.

\section{Personal finance}

The first regression model examined the contributions of Acquired Financial Knowledge and allocations of monthly income (i.e., Rent, Credit Card, Savings Account) in predicting Age Group (i.e., Younger vs. Older). Collectively, these variables made a significant contribution in predicting whether an individual was a Younger or Older participant. Inspection of the partial test for individual variables revealed that Acquired Financial Knowledge significantly predicted a participant's Age Group. Specifically, the odds that an individual was an Older participant were 1.68 greater for every unit increase in Acquired Financial Knowledge. Said another way, for every one-point increase in Acquired Financial Knowledge, the odds that an individual was an Older participant increased by $68 \%{ }^{2}$.

After controlling for Acquired Financial Knowledge, Credit Card Allocation $(p=0.038)$ and Savings Account Allocation $(p<0.0001)$ were significantly predictive of Age Group. That is, for each one-point increase in allocation toward the credit card payment, the odds of an individual being an Older participant increased by $10 \%$. By contrast, a one-point increase in allocation

\footnotetext{
${ }^{2}$ In fact, Acquired Financial Knowledge was predictive of Age Group for each of the Scenarios except Scenario 4 (Financial Management), with odds ranging from 32 to $68 \%$.
} 
Table 1 | Logistic Regression Models of FDMO Scenarios to Age (i.e., Younger vs. Older).

\begin{tabular}{|c|c|c|c|c|c|}
\hline \multirow[t]{2}{*}{ Variable } & \multirow[t]{2}{*}{$\operatorname{Exp}(b)^{*}$} & \multicolumn{2}{|c|}{$\begin{array}{l}95 \% \text { C.I. for } \\
\exp (b)\end{array}$} & \multirow[t]{2}{*}{$\begin{array}{l}\text { Partial } \\
p \text {-value }\end{array}$} & \multirow[t]{2}{*}{$\begin{array}{l}\text { Overall } \\
p \text {-value }\end{array}$} \\
\hline & & Lower & Upper & & \\
\hline \multicolumn{6}{|l|}{ PERSONAL FINANCE } \\
\hline Acquired knowledge & 1.684 & 1.234 & 2.298 & 0.001 & 0.000 \\
\hline Rent allocation & 1.004 & 0.931 & 1.082 & 0.923 & \\
\hline Credit card allocation & 1.095 & 1.005 & 1.194 & 0.038 & \\
\hline Saving account allocation & 0.923 & 0.900 & 0.947 & 0.000 & \\
\hline \multicolumn{6}{|l|}{ IMPULSE PURCHASE } \\
\hline Acquired knowledge & 1.327 & 1.017 & 1.732 & 0.037 & 0.054 \\
\hline Buy television & 0.617 & 0.300 & 1.268 & 0.189 & \\
\hline \multicolumn{6}{|c|}{ LOW PRECISION INVESTMENT } \\
\hline Acquired knowledge & 1.407 & 1.085 & 1.823 & 0.010 & 0.008 \\
\hline Decision & 1.788 & 0.952 & 3.360 & 0.071 & \\
\hline \multicolumn{6}{|c|}{ FINANCIAL MANAGEMENT } \\
\hline Acquired knowledge & 1.333 & 0.966 & 1.840 & 0.080 & 0.000 \\
\hline Savings account & 0.977 & 0.956 & 0.998 & 0.030 & \\
\hline Certificate of deposit & 1.011 & 0.993 & 1.028 & 0.235 & \\
\hline Business venture & 0.981 & 0.959 & 1.003 & 0.095 & \\
\hline Credit card payment & 0.954 & 0.777 & 1.170 & 0.649 & \\
\hline Spending & 0.968 & 0.917 & 1.022 & 0.240 & \\
\hline Managed mutual fund & 1.008 & 0.990 & 1.027 & 0.364 & \\
\hline Unmanaged mutual fund & 1.008 & 0.988 & 1.029 & 0.441 & \\
\hline \multicolumn{6}{|l|}{ FINANCIAL BEHAVIOR } \\
\hline Acquired knowledge & 1.515 & 1.150 & 1.996 & 0.003 & 0.000 \\
\hline Promotion-oriented & 0.727 & 0.576 & 0.916 & 0.007 & \\
\hline Prevention-oriented & 1.179 & 0.988 & 1.408 & 0.068 & \\
\hline
\end{tabular}

${ }^{*}$ Exp(b) values are the exponentiated regression coefficient estimates.

toward the savings account decreased the odds of an individual being an Older participant by $8 \%$ (thus, Younger participants were more likely to allocate to savings).

\section{Impulse purchase}

The second regression model examined the contribution of Acquired Financial Knowledge and a participant's decision to purchase a Television in predicting Age Group (i.e., Younger vs. Older). Together, the two variables were marginally significant $(p=0.054)$ in predicting whether an individual was a Younger or Older participant, and non-significant after controlling for Acquired Financial Knowledge.

\section{Low precision investment}

The third regression model examined the contribution of Acquired Financial Knowledge and a participant's decision whether to invest money based on minimal information in predicting Age Group (i.e., Younger vs. Older). Collectively, both variables predicted whether an individual was a Younger or Older participant. After controlling for Acquired Financial Knowledge, there was a trend toward Older participants being more likely to make a decision with minimal information as compared to Younger participants $(p=0.07)$.

\section{Financial management}

In the fourth regression model, we examined the contribution of Acquired Financial Knowledge and inheritance allocations (i.e., Savings Account, Certificate of Deposit, Business Venture, Credit Card Payment, Spending, Managed Mutual Fund, Unmanaged Mutual Fund) in predicting Age Group (i.e., Younger vs. Older). Taken together, these variables predicted whether an individual was a Younger or Older participant based on inheritance allocations. Inspection of the partial test indicated that after controlling for the effect of Acquired Financial Knowledge and other inheritance allocations (i.e., Certificate of Deposit, Business Venture, Credit Card Payment, Spending, Managed Mutual Fund, Unmanaged Mutual Fund), only the amount allocated into the Savings Account was significantly predictive of Age Group $(p=0.03)$. In particular, every percentage increase in amount placed in the Savings Account decreased the odds of an individual being an Older participant by $2 \%$. Said differently, Younger participants were significantly more likely to place money into a savings account.

\section{Financial behavior}

In the final model, we examined the contribution of Acquired Financial Knowledge and an individual's behavior toward investment (i.e., gaining money or promotion-oriented vs. avoiding monetary loss or prevention-oriented) in predicting Age Group (i.e., Younger vs. Older). Overall, the model was predictive of Age Group. Partial test inspections revealed that an increase in onepoint on promotion-oriented responses decreased the odds of an individual being an Older participant by $27 \%(p=0.007)$. In other words, Younger participants were significantly more likely to make decisions toward gaining money. (There was a trend toward Older participants being more likely to make decisions toward avoiding monetary loss, $p=0.07$.)

\section{SEX ANALYSES}

Table 2 displays the results from the logistic regression analyses of responses to the FDMQ Scenarios between Older Male and Female participants.

\section{Personal finance}

The first regression model examined the contribution of Acquired Financial Knowledge and allocations of monthly income (i.e., Rent, Credit Card, Savings Account) in predicting Sex (i.e., Male vs. Female). Together, this group of variables predicted whether an individual was a Male or Female participant. For this model, Acquired Financial Knowledge, after controlling for the effect of response to the scenario, was non-significant predicting Sex of a participant ${ }^{3}$. Inspection of the partial test for individual variables revealed that after controlling for Acquired Financial Knowledge, Credit Card Allocation $(p<0.05)$, and Savings Account Allocation $(p=0.017)$ were significant in predicting Sex of a participant. That is, for every unit increase in Credit Card payment, the odds of an individual being a Male participant increased by $14 \%$. Similarly, for every unit increased in Savings Account allocation, the odds of an individual being a Male participant increased by $5 \%$.

\footnotetext{
${ }^{3}$ Acquired Financial Knowledge was non-significant in predicting Sex of a participant for all subsequent models, after controlling for the effect of response to the scenario.
} 
Table 2 | Logistic Regression Models of FDMO Scenarios to Sex (i.e., Male vs. Female).

\begin{tabular}{|c|c|c|c|c|c|}
\hline \multirow[t]{2}{*}{ Variable } & \multirow[t]{2}{*}{$\operatorname{Exp}(b)^{*}$} & \multicolumn{2}{|c|}{$\begin{array}{l}95 \% \text { C.I. for } \\
\operatorname{exp(b)}\end{array}$} & \multirow[t]{2}{*}{$\begin{array}{l}\text { Partial } \\
p \text {-value }\end{array}$} & \multirow[t]{2}{*}{$\begin{array}{l}\text { Overall } \\
p \text {-value }\end{array}$} \\
\hline & & Lower & Upper & & \\
\hline \multicolumn{6}{|l|}{ PERSONAL FINANCE } \\
\hline Acquired knowledge & 0.596 & 0.343 & 1.035 & 0.066 & 0.005 \\
\hline Rent allocation & 0.888 & 0.692 & 1.139 & 0.349 & \\
\hline Credit card allocation & 0.860 & 0.742 & 0.996 & 0.044 & \\
\hline Saving account allocation & 0.953 & 0.916 & 0.991 & 0.017 & \\
\hline \multicolumn{6}{|l|}{ IMPULSE PURCHASE } \\
\hline Acquired knowledge & 0.754 & 0.485 & 1.174 & 0.212 & 0.378 \\
\hline Buy television & 0.855 & 0.307 & 2.377 & 0.855 & \\
\hline \multicolumn{6}{|c|}{ LOW PRECISION INVESTMENT } \\
\hline Acquired knowledge & 0.742 & 0.477 & 1.154 & 0.185 & 0.236 \\
\hline Decision & 0.631 & 0.235 & 1.696 & 0.361 & \\
\hline \multicolumn{6}{|c|}{ FINANCIAL MANAGEMENT } \\
\hline Acquired knowledge & 0.679 & 0.383 & 1.203 & 0.184 & 0.064 \\
\hline Savings account & 0.948 & 0.892 & 1.006 & 0.079 & \\
\hline Certificate of deposit & 0.953 & 0.899 & 1.010 & 0.105 & \\
\hline Business venture & 0.946 & 0.887 & 1.009 & 0.092 & \\
\hline Credit card payment & 0.846 & 0.478 & 1.498 & 0.566 & \\
\hline Spending & 0.891 & 0.794 & 1.000 & 0.050 & \\
\hline Managed mutual fund & 0.952 & 0.897 & 1.011 & 0.107 & \\
\hline Unmanaged mutual fund & 0.936 & 0.880 & 0.994 & 0.032 & \\
\hline \multicolumn{6}{|l|}{ FINANCIAL BEHAVIOR } \\
\hline Acquired knowledge & 0.766 & 0.481 & 1.218 & 0.259 & 0.547 \\
\hline Promotion-oriented & 1.039 & 0.770 & 1.403 & 0.802 & \\
\hline Prevention-oriented & 1.084 & 0.841 & 1.395 & 0.534 & \\
\hline
\end{tabular}

${ }^{*} \operatorname{Exp}(b)$ values are the exponentiated regression coefficient estimates.

\section{Impulse purchase}

The second regression model examined the contribution of Acquired Financial Knowledge and a participant's decision to purchase a Television to predicting Sex (i.e., Male vs. Female). The model indicated that the decision to make an impulse purchase was non-significant in predicting Sex of a participant.

\section{Low precision investment}

The third regression model examined the contribution of Acquired Financial Knowledge and a participant's decision whether to invest money based on minimal information in predicting Sex (i.e., Male vs. Female). The overall model suggests that both variables were non-significant in predicting Sex of a participant.

\section{Financial management}

In the fourth regression model, we examined the contribution of Acquired Financial Knowledge and inheritance allocations (i.e., Savings Account, Certificate of Deposit, Business Venture, Credit Card Payment, Spending, Managed Mutual Fund, Unmanaged Mutual Fund) in predicting Sex (i.e., Male vs. Female). Collectively, these variables were marginally significant in predicting whether an individual was a Male or Female participant based on inheritance allocations. After controlling for the effect of
Acquired Financial Knowledge and other inheritance allocations, only the amount allocated into Spending $(p=0.05)$ and Unmanaged Mutual Fund $(p=0.032)$ were significantly predictive of Sex of a participant. In particular, every percentage increase in amount placed in Spending increased the odds of an individual being a Male participant by $11 \%$. Similarly, every percentage increase in amount placed in an Unmanaged Mutual Fund increased the odds of an individual being a Male participant by $6 \%$.

\section{Financial behavior}

In the final model, we examined the contribution of Acquired Financial Knowledge and a participant's behavior toward investment (i.e., gaining money or promotion-oriented vs. avoiding monetary loss or prevention-oriented) in predicting Sex of a participant. Overall, the model was non-significant in predicting Sex of a participant.

\section{CORRELATIONAL ANALYSES}

Pearson's $r$ correlations were conducted in order to examine the associations between responses to the FDMQ Scenarios and neuropsychological performance, among the Older participants (see Table 3). A single composite variable was computed for the FDMQ based upon the justifications participants provided for each of their financial decisions (hereafter referred to as Depth of Reasoning). To do this, scores were calculated based upon the collective responses to seven short answer questions found throughout Scenarios 1,2 , and 4 , in which participants were asked to justify why they had made each preceding monetary decision. Responses were graded on a 3-point scale, with those answers showing the greatest comprehension and sophistication (i.e., one must pay the credit card bill to avoid interest accrual and future rate increases) receiving higher scores than those that simply restated the question (i.e., you must pay the bill because it is due this month).

Correlational analyses revealed several significant correlations. In terms of demographic variables, Depth of Reasoning correlated with Age $(r=-0.24)$ and Education $(r=0.21)$. That is, as age increased, Depth of Reasoning among Older participants declined (was poorer). Too, Older participants with higher levels of educational attainment provided stronger Depth of Reasoning for the FDMQ Scenarios.

There was an absence of association between Depth of Reasoning and the neuropsychological domains of Premorbid Intellect, Attention and Working Memory, Numerical Skill, Visual Spatial, Language, and Memory (average $r=10.091$ ). By contrast, Current Intelligence and Executive Functioning were associated with Depth of Reasoning. Specifically, two measures of non-verbal current intelligence (WASI Block Design and Matrix Reasoning) were positively and significantly associated with Depth of Reasoning ( $r=0.31$ and $r=0.21$, respectively). For the cognitive domain of Executive Functioning, all variables were significantly associated with Depth of Reasoning. That is, on a test of problem solving and mental flexibility (WCST Perseverative Errors), Depth of Reasoning decreased as number of Perseverative Errors increased $(r=-0.24)$. Similarly, on a test of simple executive functions involving speeded set-shifting (Trail Making B), Depth of Reasoning decreased as time to complete the task increased $(r=-0.22)$. Lastly, on a laboratory task of decision-making, the IGT, Depth 
Table 3 | Association of FDMO Depth of Reasoning with Neuropsychological Performance.

\begin{tabular}{|c|c|c|c|}
\hline Characteristics & Mean (SD) & Pearson $r$ & Significance \\
\hline \multicolumn{4}{|l|}{ DEMOGRAPHICS } \\
\hline Age (years) & $73.62(8.60)$ & $-0.239 *$ & 0.015 \\
\hline Education (years) & $15.97(2.72)$ & $0.211^{*}$ & 0.032 \\
\hline \multicolumn{4}{|c|}{ PREMORBID AND CURRENT INTELLIGENCE } \\
\hline WRAT-3 Reading & $51.36(4.00)$ & 0.128 & 0.205 \\
\hline WASI Vocabulary & $66.65(6.86)$ & 0.099 & 0.322 \\
\hline WASI Similarities & $38.55(4.26)$ & 0.068 & 0.493 \\
\hline WASI Block Design & $36.61(11.44)$ & $0.307^{* *}$ & 0.002 \\
\hline WASI Matrix Reasoning & $23.07(6.12)$ & $0.205^{*}$ & 0.038 \\
\hline \multicolumn{4}{|c|}{ ATTENTION AND WORKING MEMORY } \\
\hline WAIS-III Digit Span & $17.17(3.90)$ & 0.002 & 0.984 \\
\hline WAIS-III Letter-Number & $10.11(2.50)$ & 0.100 & 0.316 \\
\hline \multicolumn{4}{|l|}{ NUMERICAL SKILL } \\
\hline WAIS-III Arithmetic & $14.51(3.36)$ & 0.127 & 0.204 \\
\hline Numeracy & $8.25(2.35)$ & 0.133 & 0.183 \\
\hline \multicolumn{4}{|l|}{ VISUAL SPATIAL } \\
\hline Benton Facial Recognition & $46.77(4.19)$ & 0.115 & 0.255 \\
\hline Rey-O Complex Figure Copy & $32.45(2.82)$ & -0.060 & 0.552 \\
\hline \multicolumn{4}{|l|}{ LANGUAGE } \\
\hline COWAT & $44.17(11.66)$ & 0.023 & 0.822 \\
\hline Boston Naming Test & $18.75(1.47)$ & 0.095 & 0.373 \\
\hline \multicolumn{4}{|l|}{ MEMORY } \\
\hline AVLT 30 min Delay & $9.90(2.85)$ & 0.070 & 0.484 \\
\hline Rey-O Complex Figure Delay & $16.26(6.50)$ & 0.155 & 0.122 \\
\hline BVRT-R Errors & $4.36(2.37)$ & 0.109 & 0.285 \\
\hline \multicolumn{4}{|c|}{ EXECUTIVE FUNCTIONING } \\
\hline WCST Perseverative Errors & $11.58(9.70)$ & $-0.237^{*}$ & 0.020 \\
\hline Trail Making B & $78.94(29.32)$ & $-0.216^{*}$ & 0.030 \\
\hline lowa Gambling Task & $12.14(38.01)$ & $0.205^{*}$ & 0.041 \\
\hline
\end{tabular}

${ }^{*} p<0.05 ;{ }^{*} p<0.01$

of Reasoning increased with higher levels of risk aversiveness $(r=0.21)$.

\section{DISCUSSION}

The present exploratory study compared how healthy Younger and Older participants make a series of increasingly complex financial decisions. Additionally, among the Older participants, we examined the contribution of demographic and neuropsychological variables to financial decision-making ability. The study yielded multiple findings. Older participants outperformed Younger participants on a multiple-choice test of Acquired Financial Knowledge, a finding that may be due in part to the experience conferred by age. Nevertheless, even after controlling for this preexisting financial knowledge, several important, and striking differences were observed between Younger and Older participants throughout the FDMQ.

In both the Personal Finance and Financial Management scenarios, Younger participants were more likely to place money into a Savings Account than were Older participants. By contrast, Older participants were more likely to pay off their Credit Card bills in the Personal Finance scenario than were Younger participants. Older participants also displayed greater interest in making immediate decisions regarding the allocation of an unexpected inheritance during the Low Precision Investment scenario of the FDMQ, whereas the Younger participants exhibited a preference for delaying decision-making until additional resources could be accessed. Furthermore, Older participants rated themselves as having significantly less interest in using the hypothetical inheritance funds for purposes of monetary gain (i.e., a promotion orientation) than Younger participants, while also displaying a trend of favoring investment strategies which avoided potential monetary loss (i.e., a prevention orientation).

Among the Older participants, few differences were demonstrated between the two sexes. However, we did observe that Males were more likely to pay their Credit Card bill and contribute money to a Savings Account in the Personal Finance scenario than Females. Males were also more likely to allocate money to the Savings Account and Unmanaged Mutual Fund options than Females, during the Financial Management scenario. Reasons for these sex preferences are unknown, though it may be speculated that Older Males' preference for investment in an Unmanaged Mutual Fund stems from their greater experience and comfort with investing (Ozerol et al., 2011).

Among the Older participants, multiple significant correlations were found between the FDMQ Depth of Reasoning composite variance and performance on aspects of the neuropsychological battery. Depth of Reasoning was positively correlated with nonverbal intelligence and executive functioning. Level of education was also positively correlated with Depth of Reasoning scores. Too, age showed an inverse correlation with Depth of Reasoning such that the ability to justify one's financial decisions significantly declined with increasing age. Finally, we did not observe an association between numerical skill and FDMQ Depth of Reasoning, which came as somewhat of a surprise given that Marson et al. (2000) found that changes in basic numerical skills, such as the ability to perform simple calculations, were one of the strongest predictors of a loss of financial capacity in patients with Alzheimer's disease.

Taken together, our findings are supported by the work of Korniotis and Kumar (2010), who similarly deduced that sound cognitive abilities play a critical role in the capacity to make high quality financial decisions across the lifespan. However, the relationship between cognitive fitness and financial decisionmaking capacity is complex and difficult to characterize. Although the experience and financial knowledge accumulated by older investors would be predicted to buffer age-associated declines, the cognitive declines associated with normal aging may offset such safeguards by preventing the effective application of previously learned principles (Korniotis and Kumar, 2010).

Ultimately, it may be this underlying decline in cognition associated with normal aging that accounts for the trend observed in the Low Precision Investment scenario whereby Older participants preferred to make immediate investment decisions while Younger participants seek out more information. In a simulated financial decision-making task involving maximizing profit at a yard sale, Chen and Sun (2003) found that younger and older adults adopted different strategies (although age did not ultimately predict total 
monetary gain). While younger adults demonstrated flexibility by switching strategies as needed during the task, older adults adopted a consistent and less memory-demanding strategy. These findings imply that advancing age can lead to a preferential selection of less cognitively demanding decision-making strategies (Chen and Sun, 2003). So it may be in the present study that the Older participants preferred to make an immediate decision with regards to an unexpected inheritance in an effort to reduce cognitive load, whereas the Younger participants did not because no such cognitive burden was experienced.

Interestingly, our age-related financial decision-making findings are notably similar to the literature examining the effect of aging on medical decision-making. That is, the medical decisionmaking literature has indicated that older adults demonstrate declines in the thoroughness of the information search process and in the amount of information used (Meyer et al., 1995; Zwahr et al., 1999), as well as a shorter interval between symptom onset and the decision to seek medical care (Leventhal et al., 1993, 1995). Such findings have been interpreted as suggesting that older adults may be may be attempting to conserve diminishing cognitive and emotional resources by making medical decisions in the aforementioned manner.

With regard to sex differences, Older participants were more likely to pay the Credit Card Bill and invest in the Savings Account option each time it was presented. Interestingly, a study of sexspecific risk attitudes among undergraduates at the University of Zurich and the Swiss Federal Institute found a similar tendency for males to make less risky financial choices than females under controlled economic parameters (Schubert et al., 1999). However, given the cross-sectional nature of the present study and the absence of demographic data on the Younger participants, it cannot be empirically determined at this time whether the observed sex differences are stable throughout the lifespan or if they would have been displayed by the college-aged cohort. Not being able to examine this empirically is an obvious limitation of the current study.

Given the utility of the FDMQ as shown in the present work, directions for future research should focus on expanding the population under study, and the inclusion of neuroimaging technology in order to empirically assess the brain regions associated with real-world financial decision-making and the effects of aging and cognitive decline on performance at the biological level. Knutson and Bossaerts (2007) have previously used functional neuroimaging to systematically measure patterns of

\section{REFERENCES}

Barrash, J., Cross, S., and Manzel, K. (1999). The validity of Boston Naming Test short forms. J. Int. Neuropsychol. Soc. $5,118$.

Bechara, A. (2007). Iowa Gambling Task (IGT) Professional Manual. Lutz: Psychological Assessment Resources.

Benton, A. L. (1945). A visual retention test for clinical use. Arch. Neurol. Psychiatry 54, 212-216.

Benton, A. L., and Hamsher, K. (1989). Multilingual Aphasia
Examination. Iowa City, IA: AJA Associates.

Benton, A. L., Sivan, A. B., Hamsher, K, Varney, N. R., and Spreen, O. (1994). Contributions to Neuropsychological Assessment: A Clinical Manual, 2nd Edn. New York, NY: Oxford University Press.

Boersch-Supan, A. H., and Essig, L. (2005). "Household savings in Germany: results of the first SAVE study," in Analyses in the Economics of Aging, ed. D. A. Wise (Chicago: University of Chicago Press), 317-356.

neural activation during a task of basic financial decision-making. The experimenters manipulated expected value by varying the magnitude and probability of monetary reward, finding that anticipatory activation of the ventral striatum predicted risky financial investment choices, whereas anticipatory activation of the insula predicted safe investments. Interestingly, neither pattern of activation was significantly associated with either optimal or suboptimal investment decisions (Knutson and Bossaerts, 2007).

The present study also has noteworthy implications for future research and public policy. Further studies should explore the tendency observed among older adults to make immediate financial decisions, investigating whether interventions might be designed to facilitate this population in using their extensive financial knowledge to evaluate all of the available information before committing to financial investments. Additionally, if future research is able to replicate the findings that men, particularly older males, are more likely to pay credit card bills and utilize savings accounts than women, this would be a significant focus for public policy targeting older females. Because the life expectancy of women is significantly higher than that of men, there are a population segment of older women who may be thrust into the financial decision-making arena following the (often unexpected) death of a spouse. Consequently, these older adults might benefit from targeted education and intervention attempts.

In consideration of the present findings, and those of Korniotis and Kumar (2010), that financial decision-making performance drops steadily after age 70 relative to what prior performances would predict, participation in the stock market and other complex financial endeavors may not be in the best interest of some older adults irrespective of prior experience, particularly with advancing age. Furthermore, legal protections must be put in place to ensure that at-risk older adults are not extorted by those seeking to benefit from the impaired financial decision-making abilities of this population. This issue will become even more pressing as more financial and business transactions begin to take place online and older adults are faced with learning entirely new ways to perform previously well-known tasks, such as bill payment and electronic funds transfers.

\section{ACKNOWLEDGMENTS}

Preparation of this article was supported by a National Institute on Aging Career Development Award (K01 AG022033) to Natalie L. Denburg.

Chen, Y., and Sun, Y. (2003). Age differences in financial decision-making: using simple heuristics. Educ. Gerontol. 29, 627-635.

Cole, C. A., and Denburg, N. L. (2008). Financial Decision Making Questionnaire (FDMQ). Iowa City, IA: University of Iowa Carver College of Medicine, Department of Neurology.

Denburg, N. L., Cole, C. A., Hernandez, M., Yamada, T. H., Tranel, D., Bechara, A., and Wallace, R. B. (2007). The orbitofrontal cortex, real-world decision-making, and normal aging. Ann. N. Y. Acad. Sci. 1121, 480-498.

Denburg, N. L., and Harshman, L. (2010). "Why so many seniors get swindled: brain anomalies and poor decision-making in older adults," in The Dana Foundation's Cerebrum: Emerging Ideas in Brain Science (New York: Dana Press), 123-131.

Denburg, N. L., Recknor, E. C. Bechara, A., and Tranel, D. (2006). Psychophysiological anticipation of positive outcomes promotes 
advantageous decision-making in normal older persons. Int. J. Psychophysiol. 61, 19-25.

Denburg, N. L., Tranel, D., and Bechara, A. (2005). The ability to decide advantageously declines prematurely in some normal older persons. Neuropsychologia 43, 1099-1106.

Federal Interagency Forum on AgingRelated Statistics. (2010). Older Americans 2010: Key Indicators of Well-Being. Washington, DC: Government Printing Office.

Finucane, M. L., Slovic, P., Hibbard, J. H., Peters, E., Mertz, C. K., and MacGregor, D. G. (2002). Aging and decision-making competence: an analysis of comprehension and consistency skills in older versus younger adults considering healthplan options. J. Behav. Decis. Mak. 15, 141-164.

He, W., Sengupta, M., Velkoff, V. A., and DeBarros, K. A. (2005). 65+ in the United States: 2005. U.S. Census Bureau, Current Population Reports, P23-209. Washington, DC: U.S. Government Printing Office.

Heaton, R. K., Chelune, G. J., Talley, J. L., Kay, G. G., and Curtiss, G. (1993). Wisconsin Card Sorting Test Manual: Revised and Expanded. Odessa, FL: Psychological Assessment Resources.

John, D. R., and Cole, C. A. (1986). Age differences in information processing: understanding deficits in young and elderly consumers. J. Consum. Res. 13, 297-315.

Kaplan, E. F., Goodglass, H., and Weintraub, S. (1983). Boston Naming Test. Philadelphia, PA: Lea \& Febiger.

Knutson, B., and Bossaerts, P. (2007). Neural antecedents of financial decisions. J. Neurosci. 27, 8174-8177.
Korniotis, G. M., and Kumar, A. (2010). "Cognitive abilities and financial decisions," in Behavioral Finance, eds H. K. Baker and J. R. Nofsinger (Hoboken, NJ: John Wiley \& Sons, Inc.), 559-576.

Leventhal, E. A., Easterling, D., Leventhal, H., and Cameron, L. (1995). Conservation of energy, uncertainty reduction, and swift utilization of medical care among the elderly: study II. Med. Care 33, 988-1000.

Leventhal, E. A., Leventhal, H., Schaefer, P., and Easterling, D. (1993). Conservation of energy, uncertainty reduction, and swift utilization of medicalcare among the elderly. $J$. Gerontol. 48, 78-86.

Lipkus, I. M., Samsa, G., and Rimer, B. K. (2001). General performance on a numeracy scale among highly educated samples. Med. Decis. Making 21, 37-44.

Lusardi, A. (2010). Americans' Financial Capacity. Report prepared for the Financial Crisis Inquiry Commission, Washington, DC.

Lusardi, A., and Mitchell, O. S. (2011a). Financial literacy across the world: an overview. J. Pension Econ. Financ. 10, 497-508.

Lusardi, A., and Mitchell, O. S. (2011b). "Financial literacy and planning: implications for retirement wellbeing," in Financial Literacy: Implications for Retirement Security and the Financial Marketplace, eds O. S. Mitchell and A. Lusardi (New York, NY: Oxford University Press), 17-39.

Marson, D. C., Sawrie, S. M., Snyder, S., McInturff, B., Stalvey, T., Boothe, A., Aldridge, T., Chatterjee, A., and Harrell, L. E. (2000). Assessing financial capacity in patients with Alzheimer disease: a conceptual model and prototype instrument. Arch. Neurol. 57, 877-884.
Meyer, B. J. F., Russo, C., and Talbot, A. (1995). Discourse processing and problem solving: decisions about the treatment of breast cancer by womenacross the life span. Psychol. Aging 10, 84-103.

Moye, J., and Marson, D. C. (2007). Assessment of decision-making capacity in older adults: an emerging area of practice and research. $J$. Gerontol. 62, 3-11.

Ozerol, H., Camgoz, S. M., Karan, M. B., and Ergeneli, A. (2011). Determining the performance of individual investors: the predictive roles of demographic variables and trading strategies. Int. J. Bus. Soc. Sci. 2, 86-92.

Rey, A. (1941). L'examen psychologique dans les cas d'encephalopathie traumatique. Arch. Psychol. 28, 286-340.

Rey, A. (1964). L'examen Clinique en Psychologie. Paris: Presses Universitaires de France.

Schubert, R., Brown, M., Gysler, M., and Brachinger, H. W. (1999). Financial decision-making: are women really more risk-averse? Am. Econ. Rev. 89 , 381-385.

Spreen, O., and Strauss, E. (1998) A Compendium of Neuropsychological Tests, 2nd Edn. New York, NY: Oxford University Press.

Tranel, D., Benton, A., and Olson, K. (1997). A 10-year longitudinal study of cognitive changes in elderly persons. Dev. Neuropsychol. 13 87-96.

Triebel, K. L., Martin, R., Griffith, H. R., Marceaux, J., Okonkwo, O. C., Harrell, L., Clark, D., Brockington, J., Bartolucci, A., and Marson, D. C. (2009). Declining financial capacity in mild cognitive impairment. Neurology 73, 928-934.

United Nations. (2009). World Population Ageing 2009. New York, NY: United Nations.
Wechsler, D. A. (1997). Wechsler Adult Intelligence Scale-III. New York, NY: Psychological Corporation.

Wechsler, D. A. (1999). Wechsler Abbreviated Scale of Intelligence. New York, NY: Psychological Corporation.

Wilkinson, G. S. (1993). Wide Range Achievement Test - 3. Wilmington, DE: Jastak Associates, Inc.

Yoon, C., Cole, C. A., and Lee, M. (2009). Consumer decision making and aging: current knowledge and future directions. J. Consum. Psychol. 19, 2-16.

Zwahr, M. D., Park, D. C., and Shifren, K. (1999). Judgments about estrogen replacement therapy: the role of age, cognitive abilities, and beliefs. Psychol. Aging 14, 179-191.

Conflict of Interest Statement: The authors declare that the research was conducted in the absence of any commercial or financial relationships that could be construed as a potential conflict of interest.

Received: 13 December 2011; paper pending published: 09 January 2012; accepted: 16 May 2012; published online: 15 June 2012.

Citation: Shivapour SK, Nguyen CM, Cole CA and Denburg NL (2012) Effects of Age, Sex, and Neuropsychological Performance on Financial DecisionMaking. Front. Neurosci. 6:82. doi: 10.3389/fnins.2012.00082

This article was submitted to Frontiers in Decision Neuroscience, a specialty of Frontiers in Neuroscience.

Copyright (c) 2012 Shivapour, Nguyen, Cole and Denburg. This is an open-access article distributed under the terms of the Creative Commons Attribution Non Commercial License, which permits noncommercial use, distribution, and reproduction in other forums, provided the original authors and source are credited. 